\title{
Research and Review on the Development of Mechanical and Electrical Integration of System Function Principle and Related Technologies
}

\author{
Zhihai Zhou $^{1}$ \\ ${ }^{1}$ Langfang Polytechnic Institute, \\ Langfang,Hebei,China
}

\begin{abstract}
In this paper, we conduct research on the development of mechanical and electrical integration of system function principle and related technologies. Along with the rapid and continuous development of modern science and technology, it's for the penetration and cross of different subjects great push, the more important is caused by technological revolution in the field of engineering and mechanical engineering field under the rapid development of computer technology and microelectronic technology and penetration to the mechanical and electrical integration, which is formed by the mechanical industry lead to trigger a particularly large changes in the mechanical industry management system and mode of production, product and technical structure, composition and function, thus result in industrial production from the previous mechanical electrification progressively electromechanical integration which lead the trend of the current technology.
\end{abstract}

Keywords: Mechanical and Electrical Integration; System Function; Development Principle.

\section{Introduction}

Electromechanical integration technology, is made up of microelectronics technology, computer technology and servo drive technology and mechanical technology with the combination of comprehensive technology, microelectronics technology, computer is the product of technology to the mechanical technology constantly infiltration. Mechanical technology is the foundation of the electromechanical integration technology. With the introduction of machinery industry, high-tech mechanical technology is faced with challenge and change. In electromechanical integration products, it is no longer a single system, but the system structure, weight, volume, rigidity and durability aspect has important effect on mechanical and electrical integration system. Electromechanical integration products are composed of multiple technologies and related part of the complex and mechanical and electrical integration technology is cross each other by a variety of techniques, permeable formation of the edge of a comprehensive technology, it has a very wide range of technologies involved. The general parts of the technique could be summarized as the follows. (1) Detection and sensor technology. In electromechanical integration products, the working process of various parameters, working status and related to the working process of the relevant information will be received through the sensor, and through the corresponding signal detection device to measure, and then send people information processing device and feedback to control device, in order to realize the working process of the general automatic control products. (2) Automatic control technology. The expansion of the electromechanical integration products in the automatic control function, make the product precision and efficiency are increased quickly. Through automatic control, electromechanical integration products can find fault in time, work in process and implementation of automatic switch, reduces downtime which will increase the effective utilization of equipment. (3) Precision machinery technology. Mechanical technology is foundation 
of the electromechanical integration technology, because the main function and structure of mechatronics products functions were achieved by mechanical technology is given priority to. In mechanical drive and control the process of mutual combination of electronic technology, mechanical technology put forward higher requirements, such as transmission precision and accuracy requirements compared with the traditional mechanical technology had the very big enhancement. (4) Information processing technology. Information processing technology is to point to in the working process of the electromechanical integration products, and the working process of the various parameters and status as well as the automatic control on the exchange of information, access, operation, judgment and decision analysis, etc. Computer technology includes hardware and software technology, network and communication technology, data processing technology and database technology. In electromechanical integration products, computer information processing device is the core of the product, its control and direct the operation of the electromechanical integration products [1-2]. In the following figure one, we illustrate the development of the mechanical and electrical integration visually.

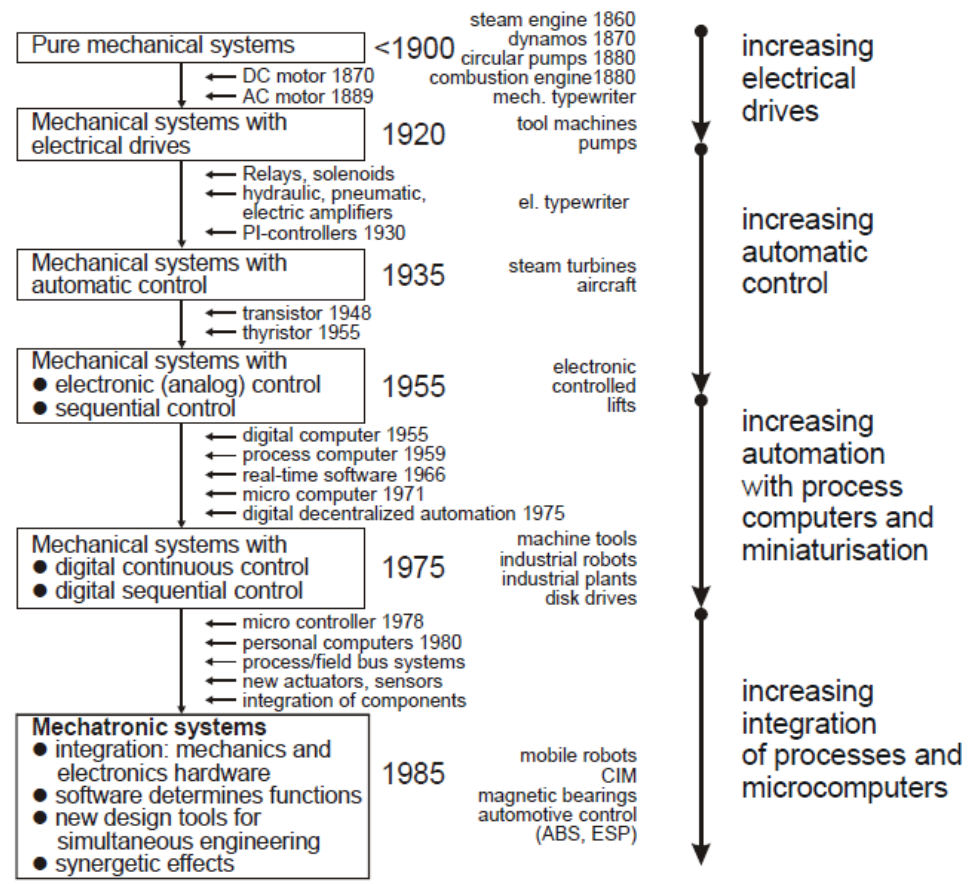

Figure 1.The Development History of the Mechanical and Electrical Integration

In this paper, we conduct research on the development of mechanical and electrical integration of system function principle and related technologies. Mechatronics system design is a kind of composite technology, it needs the support and cooperation of many departments industry, in order to obtain satisfactory results, we should not only to the electromechanical integration of the relevant technology to conduct the comprehensive understanding, but also from the concept of system engineering, through the system overall design to the formation of organic combination of related technologies, and attention should be paid to analyze and solve the new problems appeared in the process of technology integration only in this way could we able to meet the rapid development of electromechanical integration system. 


\section{The Proposed Methodology}

The Principles of Mechanical and Electrical Integration. The traditional electromechanical integration technology in the 1960s after get rapid development, including the United States and Japan in the development of electromechanical integration products and applications has been in a leading position, thanks to the solid industrial foundation between the two countries and the development of the microelectronics industry. After 1990s, with the deepening of the electro mechanical integration transformation, electromechanical integration technology in the optical, fine processing, communications technology and other fields, and integrates light appeared and micro electro mechanical integration concepts. At the same time, with the rapid development of the electromechanical integration technology and advanced control technology, machine vision technology, optical fiber manufacturing technology such as the rapid development of the multidisciplinary. The development of the techniques could be summarized as the following stages. In the $1960 \mathrm{~s}$ as the first stage, this stage is called the primary stage. In this period, people consciously or unconsciously use the preliminary results of electronic technology to improve the performance of mechanical products. Special enough after the second world wars, war stimulate the combination of mechanical products and electronic technology. At that time, the research and development from the overall is still in the spontaneous condition. Because at that time, the development of electronic technology has yet to reach a certain level, the combination of mechanical technology and electronic technology is not possible, "the extensive and in-depth development, has developed a large number of promotion of products is also unable to. Mechanical engineering technology have a pure technical development to mechanical electrification, still belongs to the traditional machinery. Its main function is still sufficient to replace and set fire to the physical. It is the development to the mechanical and electrical integration, one of the microelectronic devices in addition to replace some mechanical parts of the original function of gladiator, also can give a lot of new functions. In the following figure two, we demonstrate the modern mechanical and electrical integration system.

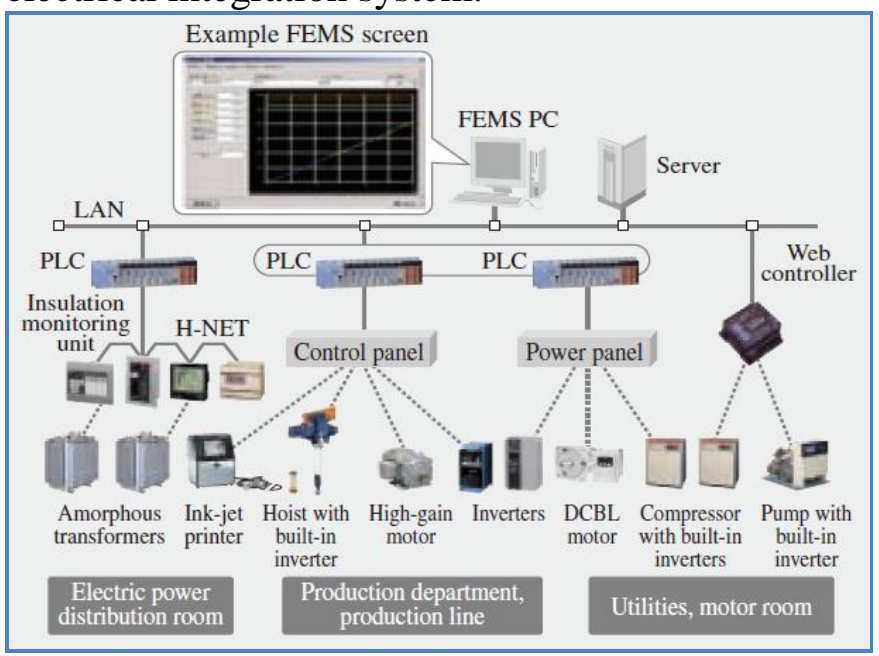

Figure 2.The Example of the Modern Mechanical and Electrical Integration System

The Applications of Mechanical and Electrical Integration Technique. With the advancement of China's industrial modernization and the rapid development of computer technology, mechatronics technology obtained the unprecedented development and the general concept of electromechanical integration has been widely accepted and obtained the widespread application.

Robotics is a typical electromechanical integration technology, and with the advancement of industrial modernization, industrial robots have been widely used in automobile assembly, food processing, computer equipment, and other industrial fields. The application of industrial robots, on the one hand, improve the product quality, on the other hand makes the industrial cost greatly reduced, the yield increases rapidly, profits to improve significantly. Now, with the rapid development of VLSI technology, as well as the development of advanced algorithms such as neural network and fuzzy control, has a variety of awareness, 
which can realize complex logic judgment, thinking and decision-making has been used, the third generation of intelligent robot can this kind of robot according to the scene environment to implement dynamic path planning which has obtained the good man-machine interface which can act independently in a complex environment [3].

Computer integrated manufacturing system is to point to by a multilevel computer control hardware structure, with a set of orders, sales, design, manufacture and management of integrated software system of fully automated manufacturing system. It is the latest trend in the development of manufacturing industry in the world, and its emergence, broke the traditional production sector division, and implements the management decision-making, product development to the combination of production and operation management. In construction machinery industry, as a result of the electronic science and technology into, is no longer the simple machine electrification before, but slowly in the direction of the electromechanical integration development. Telecommunication information technology into brought technical innovation for the mechanical engineering industry, machinery industry in processing mode, management mode, great changes have taken place in such aspects as production procedure, simplify the procedure of the operation of many, improve work efficiency, in the mode of management with the help of modern scientific way.

On one hand, the implementation of the mechanical and electrical integration, is the physical act of men into computer, and then the application to control the machine, in some precision and technical ways better than artificial operation, even some programs is to people's subjective idea, thinking mode into a set of procedures, apply to the work. The implementation of the mechanical and electrical integration, which is a function exercise of the single parts, after the electronic application of innovation and reform, but under the action of mechanical will be solved.

The Prospect and the Future of the Technique. The general development trend of typical electromechanical integration technology could be summarized as the follows. (1) Systematic discipline distribution. To electromechanical integration products, control and execution system has enough "redundancy", has the strong "flexible", better able to cope with emergencies. In the distribution of self-discipline system, each subsystem is work independently of each other, subsystem for the total system services. At the same time, it has itself "self-discipline", according to react to different environmental conditions. (2) Holographic systematic. Network to the global economy, the production, a joint of competition between enterprises will be globalization. Electromechanical integration once developed new products. As long as its function and original, quality is reliable, will soon be popular all over the world. Due to the popularity of the network, all kinds of remote control and monitoring technology are based on network, and remote control terminal device itself is electromechanical integration products. (3) Imitation of biological systematic. It is one of the features of systematic further with open system architecture and modeling of bus structures. System can be flexible configuration, any tailoring and combination. At the same time seeking to realize multiple subsystems coordinated control and integrated management. Electromechanical integration device in the future to the dependence of information is large, and often is in "static" in the structure is not stable, but in the dynamic is stable. (4) Modular trend. Modularity is an important and arduous project. Due to electromechanical integration products and manufacturers, research and development has a standard mechanical interface, electrical interfaces, power and environmental interface of electromechanical integration products unit is a very complicated but very 
important thing. Obviously, from electrical products to be sure the benefits of standardization, seriation, both for manufacturing unit standard mechanical and electrical integration or enterprises of electromechanical integration products, large scale will bring bright future to electromechanical integration enterprise.

\section{Conclusion}

In this paper, we conduct research on the development of mechanical and electrical integration of system function principle and related technologies. The development of modern science and technology, greatly promote the cross of different subjects and penetration which led to the revolution and reform in the field of engineering. In the field of mechanical engineering, because of the rapid development of microelectronics technology and computer technology to the mechanical industry and its mechanical and electrical integration, which is formed by the penetration of the technology of mechanical industry structure, product, organization, function and structure, mode of production and management system, great changes have taken place in industrial production is characterized by mechanical electrification entered the electromechanical integration stage of development. In the future, the development of the technique will be faster which will be meaningful.

\section{References}

[1] Ping X U, University J. Discussionson Reformin Curriculum System of Mechanical and Electrical Integration Program[J]. Journal of Wuhan Commercial Service College, 2014.

[2] Yan L I. Application of Informationalized Remote Education in Mechanical and Electrical Integration Teaching $[\mathrm{J}]$. Value Engineering, 2014.

[3] Suo J L. Thoughts on Management of Mechanical and Electrical Equipments with Resources Integration of Coal Mine[J]. Mechanical Management \& Development, 2013. 